\title{
Changes in Temperatures in Okayama Area Compared with Different Urbanization Areas, Japan
}

\author{
Noriko Sakano $^{1 *}$, Nobuyuki Miyatake ${ }^{1}$, Shoko Murakami ${ }^{1}$, Takeshi Suzue ${ }^{2}$, Tomohiro Hirao ${ }^{2}$, Keiki \\ Ogino $^{3}$
}

${ }^{1}$ Department of Hygiene, Faculty of Medicine, Kagawa University, Kagawa, Japan; ${ }^{2}$ Department of Public Health, Faculty of Medicine, Kagawa University, Kagawa, Japan; ${ }^{3}$ Department of Public Health, Okayama University Graduate School of Medicine, Dentistry and Pharmaceutical Sciences, Okayama, Japan.

Email: snoriko@med.kagawa-u.ac.jp

Received November $11^{\text {th }}, 2010$; revised January $10^{\text {th }}, 2011$; accepted March $1^{\text {st }}, 2011$.

\begin{abstract}
To investigate the changes in temperatures in Okayama area compared with different levels of three urbanization areas such as Tsuyama, Tokyo areas and Hachijo island in Japan. Data of temperatures in Okayama (1891-2009), Tsuyama (1943-2009), Tokyo areas (1876-2009) and Hachijo Island (1907-2009) in Japan was obtained from Japan Meteorological Agency. Changes in temperatures in 4 areas in Japan were analyzed and compared. By using data from 1943 to 2009, some parameters of temperatures were significantly correlated with years. The change in parameters of temperatures in Hachijo Island was calmest among 4 areas. The changes in mean temperature in August and in a year in Okayama area for 50 years were the highest (August: $1.55^{\circ} \mathrm{C}$, Year: $\left.2.05^{\circ} \mathrm{C}\right)$ among 4 areas. In addition, correlation coefficient rate between years and the number of days over $35^{\circ} \mathrm{C}$ in August in Okayama area was highest $(r=0.407, p$ $=0.0037)$. Parameters of temperatures were gradually increased with years in Okayama area, especially in recent years. However, those associations were not clearly noted in Hachijo Island. In conclusion, global warming in Okayama might be accelerated more rapidly than that in Tokyo area in recent 50 years.
\end{abstract}

Keywords: Temperature, Global Warming, Urbanization, Okayama Area

\section{Introduction}

Global warming has become a serious issue for human beings. The Fourth report of the Intergovernmental Panel on Climate Change (IPCC) at 2007 on climate change has forecast that global warming will have a major impact on health conditions [1]. Global average temperatures are projected to increase between 1.8 and $4.0^{\circ} \mathrm{C}$ by the end of 21 st century [1]. Heat waves such as Shanghai in 1998 and Paris in 2003 may be representative of the increases in short-term climate change events [2-5]. It has also reported that the levels of atmospheric $\mathrm{CO}_{2}$ concentrations are increasing since the last century [6,7]. In addition, global warming has accelerated, and changes in temperatures were remarkably noted since the 1980s, resulting in increased numbers of heat related disorder in summer [8,9].

Most cities show a large heat island phenomenon, registering $5-11^{\circ} \mathrm{C}$ warmer than surrounding rural areas
[10]. On local and regional scales, changes in land cover can sometimes exacerbate the effect of greenhouse-gas-induced warming, or even exert the largest impact on climatic conditions.

We have also previously reported that higher temperatures were closely linked to higher ambulance transports in Okayama area, Japan [11]. However, accurate analysis of warming, whether temperature is actually increasing in Okayama area and what affects this will have, remain to be investigated.

The aim of this study was to investigate the current status of global warming in Okayama. In addition, we compared various parameters of temperatures between various areas from the viewpoint of the heat island effects.

\section{Methods}

\subsection{Study Area}

Okayama area in Okayama Prefecture is on the southern 
shore of Honshu Island. The population of 700000 people is situated on Okayama area. Currently several public offices of Chugoku district are located in Okayama area. Although the surrounds of Okayama area had been used primarily as paddy fields for agriculture, recently they have undergone rapid changes, developing into residential and/or commercial areas (Figure 1).

We selected three areas, Tokyo as the city part area, and Tsuyama or Hachijo Island as the provinces, for the analysis in comparison with Okayama city, Japan.

Tsuyama area in Okayama prefecture is on the central of Chugoku area, Japan. The population of 110000 people is situated on the Tsuyama area. Tsuyama area had been used primarily as paddy fields for agriculture compared to Okayama area (Figure 1).

Tokyo area is the largest metropolitan area in Japan and its population is about 13.0 million. Tokyo central ( 8.8 million population, $621 \mathrm{~km}^{2}$ ) is located in the center of the metropolitan area, and is mostly urbanized in Japan (Figure 1).

Hachijo Island $\left(65.52 \mathrm{~km}^{2}\right)$ is located at the south from Tokyo area $(287 \mathrm{~km})$ and the population of 9000 people is situated on the Hachijo Island. Island is affected by the Kuroshio Current (in an oceanic climate zone) (Figure 1).

\subsection{Temperatures}

Daily, monthly and annual temperatures in Okayama, Tsuyama, Tokyo area and Hachijo Island in Japan for the required periods were obtained from Japan Meteorological Agency (http://www.data.jma.go.jp/obd/stats/etrn/index. php, accessed 27 Jan, 2010). Mean temperature in Au-

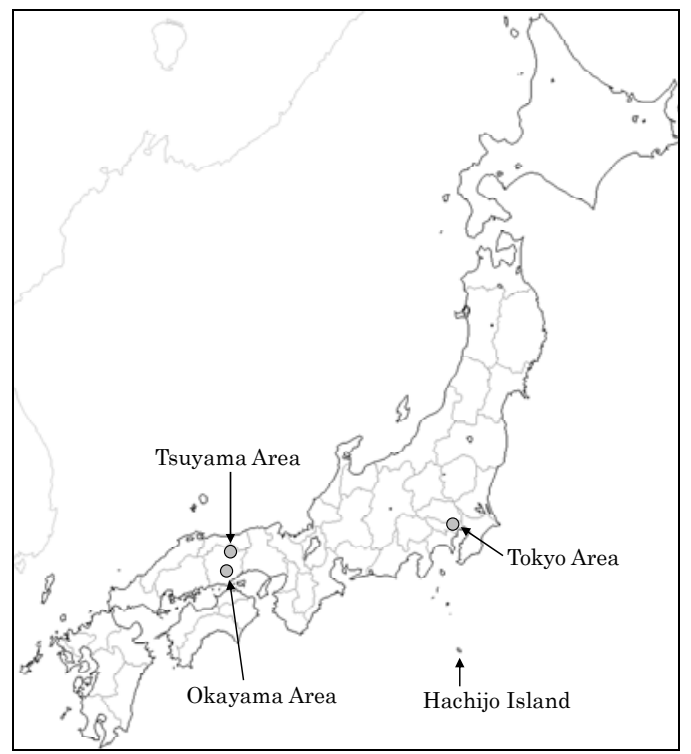

Figure 1. Four study areas in Japan. (Craft Map: http:// www.craftmap.box-i.net/map.php, accessed 6 Aug, 2010). gust, mean temperature in a year, mean of the highest temperatures in August, mean of the highest temperatures in a year, mean of the lowest temperatures in August and mean of the lowest temperatures in a year (Okayama area: 1891 2009, Tsuyama area: 1943 2009, Tokyo area: 1876 2009, Hachijo Island: 1907 2009). The number of days over the level of various temperatures in August was also used for analysis (1961 2009).

\subsection{Statistical Analysis}

Pearson's correlation analysis by using Statistical Package of SPSS 12.0J for Windows was performed to examine the significance of the linear relationship among continuous variables: $p<0.05$ was considered to be statistically significant. In addition, joinpoint regression program (National Cancer Institute Joinpoint regression program, version 3.4.3, http://srab.cancer.gov/joinpoint/, accessed 18 August, 2010) was also used to investigated the where the different lines of temperatures are connected together.

\section{Results}

Simple correlation analysis by Pearson's correlation between years and parameters of temperatures in 4 areas is summarized in Table 1. All parameters of temperatures in Okayama area (1891 2009) were significantly correlated with years. Tokyo area (1876 2009) also showed significant relationship between various parameters of temperatures and years (Table 1). In Tsuyama area, some parameters of temperatures i.e. mean temperature in a year, mean of the highest temperatures in a year and mean of the lowest temperatures in a year was significantly correlated with years.

To adjust the observation period, by using data from 1943 to 2009 , we also analyzed the relationship between various parameters of temperatures and years in 4 areas (Table 2). In Okayama area, all parameters except mean of the highest temperatures in August, were also correlated with years. Mean temperature in a year, mean of the highest temperatures in a year and mean of the lowest temperatures in a year were significantly correlated with years in Tsuyama and Tokyo areas. Mean of the lowest temperatures in August in Tokyo areas was also correlated with years. However, no parameters were correlated with years in Hachijo Island.

Correlation coefficients between various parameters of temperatures and years in Okayama area were the highest among 4 areas. From single regression line, positive change in mean temperature for 50 years was corresponded to $2.05^{\circ} \mathrm{C}$ in Okayama area, Japan (Table 2). However, the change in temperatures was the lowest in Hachijo Island among 4 areas. In addition, using single regression line in Tables 1 and 2, positive changes in temperatures 
for 50 years in Table 2 were higher than those in Table 1 in Okayama area. Therefore, positive changes in temperatures for 50 years were accelerated in Okayama area. In Tokyo areas, positive changes in mean temperature in a year and mean of the lowest temperatures in a year were also accelerated. However, other parameters in Tokyo areas and Hachijo Island were not accelerated. In addition, using joinpoint regression program, we analyzed the point of change in mean temperature in 4 different areas. The point of change in mean temperatures in Tokyo was 1921, that in Okayama was 1973 (Figure 2) and that in Tsuyama was 1984. However, the point of change in mean temperature in Hachijo Island was not noted.

Finally, the relationship between the number of days of over various temperatures which seem to be related to heat disorder is pointed out and years was also evaluated (Table 3). The number of days of over $33^{\circ} \mathrm{C}$ and $35^{\circ} \mathrm{C}$ in Okayama area was significantly correlated with years. Especially correlation coefficient between the number of days of over $35^{\circ} \mathrm{C}$ and years in Okayama area was the highest ( $r=0.407, p=0.0037)$ (Figure 3 ).

Table 1. Simple correlation analysis between years and parameters of temperature in four areas.

\begin{tabular}{lllll}
\hline & $r$ & $p$ & Single regression line & $\begin{array}{c}\text { Changes in temperatures }\left({ }^{\circ} \mathrm{C}\right) \\
\text { for } 50 \text { years }\end{array}$ \\
\hline
\end{tabular}

\section{Okayama prefecture}

\section{Okayama area (from 1891 to 2009)}

Mean temperature in August

Mean temperature in a year

Mean of the highest temperatures in August

Mean of the highest temperatures in a year

Mean of the lowest temperatures in August

Mean of the lowest temperatures in a year

Tsuyama area (from 1943 to 2009)

Mean temperature in August

Mean temperature in a year

Mean of the highest temperatures in August

Mean of the highest temperatures in a year

Mean of the lowest temperatures in August

Mean of the lowest temperatures in a year

Tokyo prefecture

Tokyo area (from 1876 to 2009)

Mean temperature in August

Mean temperature in a year

Mean of the highest temperatures in August

Mean of the highest temperatures in a year

Mean of the lowest temperatures in August

Mean of the lowest temperatures in a year

Hachijo island (from 1907 to 2009)

Mean temperature in August

Mean temperature in a year

Mean of the highest temperature in August

Mean of the highest temperature in a year

Mean of the lowest temperature in August

Mean of the lowest temperature in a year

$\begin{array}{lccc}0.416 & <\mathbf{0 . 0 0 0 1} & y=0.012 x+3.139 & 0.60 \\ 0.648 & <\mathbf{0 . 0 0 0 1} & y=0.015 x-14.969 & 0.75 \\ 0.328 & \mathbf{0 . 0 0 0 3} & y=0.012 x+8.965 & 0.60 \\ 0.668 & <\mathbf{0 . 0 0 0 1} & y=0.012 x-4.023 & 0.60 \\ 0.518 & <\mathbf{0 . 0 0 0 1} & y=0.015 x-6.511 & 0.75 \\ 0.580 & <\mathbf{0 . 0 0 0 1} & y=0.018 x-24.349 & 0.90 \\ & & & \\ 0.130 & 0.2939 & y=0.006 x+14.814 & 0.30 \\ 0.458 & <\mathbf{0 . 0 0 0 1} & y=0.014 x-13.598 & 0.70 \\ 0.043 & 0.7299 & y=0.003 x+25.890 & 0.15 \\ 0.447 & \mathbf{0 . 0 0 0 1} & y=0.014 x-8.107 & 0.70 \\ 0.132 & 0.2866 & y=0.005 x+11.671 & 0.25 \\ 0.443 & \mathbf{0 . 0 0 0 2} & y=0.014 x-18.968 & 0.70\end{array}$

$\begin{array}{llll}0.556 & <\mathbf{0 . 0 0 0 1} & y=0.018 x-8.853 & 0.90 \\ 0.887 & <\mathbf{0 . 0 0 0 1} & y=0.025 x-32.904 & 1.25 \\ 0.353 & <\mathbf{0 . 0 0 0 1} & y=0.013 x+0.6077 & 0.65 \\ 0.728 & <\mathbf{0 . 0 0 0 1} & y=0.015 x-9.010 & 0.75 \\ 0.714 & <\mathbf{0 . 0 0 0 1} & y=0.025 x-24.606 & 1.25 \\ 0.917 & <\mathbf{0 . 0 0 0 1} & y=0.033 x-53.700 & 1.65 \\ & & & \\ 0.285 & \mathbf{0 . 0 0 3 6} & y=0.006 x+15.136 & 0.30 \\ 0.350 & \mathbf{0 . 0 0 0 3} & y=0.005 x+7.624 & 0.25 \\ 0.249 & \mathbf{0 . 1 1 1 1} & y=0.007 x+15.819 & 0.35 \\ 0.290 & \mathbf{0 . 0 0 2 9} & y=0.004 x+12.482 & 0.20 \\ 0.364 & \mathbf{0 . 0 0 0 2} & y=0.008 x+8.178 & 0.40 \\ 0.416 & <\mathbf{0 . 0 0 0 1} & y=0.008 x+0.379 & 0.40\end{array}$


Table 2. Simple correlation analysis between years and parameters of temperatures in four areas from 1943 to 2009.

\begin{tabular}{|c|c|c|c|c|}
\hline & $r$ & $p$ & Single regression line & $\begin{array}{c}\text { Changes in temperatures }\left({ }^{\circ} \mathrm{C}\right) \\
\text { for } 50 \text { years }\end{array}$ \\
\hline \multicolumn{5}{|l|}{ Okayama prefecture } \\
\hline \multicolumn{5}{|l|}{ Okayama area } \\
\hline Mean temperature in August & 0.554 & $<0.0001$ & $y=0.031 x-33.852$ & 1.55 \\
\hline Mean temperature in a year & 0.833 & $<0.0001$ & $y=0.041 x-65.744$ & 2.05 \\
\hline Mean of the highest temperatures in August & 0.223 & 0.0701 & $y=0.014 x+4.996$ & 0.70 \\
\hline Mean of the highest temperatures in a year & 0.558 & $<0.0001$ & $y=0.018 x-14.764$ & 0.90 \\
\hline Mean of the lowest temperatures in August & 0.619 & $<0.0001$ & $y=0.035 x-45.840$ & 1.75 \\
\hline Mean of the lowest temperatures in a year & 0.811 & $<0.0001$ & $y=0.053 x-93.859$ & 2.65 \\
\hline \multicolumn{5}{|l|}{ Tsuyama area } \\
\hline Mean temperature in August & 0.130 & 0.2939 & $y=0.006 x+14.814$ & 0.30 \\
\hline Mean temperature in a year & 0.458 & $<0.0001$ & $y=0.014 x-13.598$ & 0.70 \\
\hline Mean of the highest temperatures in August & 0.043 & 0.7299 & $y=0.003 x+25.890$ & 0.15 \\
\hline Mean of the highest temperatures in a year & 0.447 & 0.0001 & $y=0.014 x-8.107$ & 0.70 \\
\hline Mean of the lowest temperatures in August & 0.132 & 0.2866 & $y=0.005 x+11.671$ & 0.25 \\
\hline Mean of the lowest temperatures in a year & 0.443 & 0.0002 & $y=0.014 x-18.968$ & 0.70 \\
\hline \multicolumn{5}{|l|}{ Tokyo prefecture } \\
\hline \multicolumn{5}{|l|}{ Tokyo area } \\
\hline Mean temperature in August & 0.233 & 0.0581 & $y=0.013 x+0.841$ & 0.65 \\
\hline Mean temperature in a year & 0.825 & $<0.0001$ & $y=0.035 x-52.678$ & 1.75 \\
\hline Mean of the highest temperatures in August & 0.016 & 0.8956 & $y=0.001 x+33.094$ & -0.05 \\
\hline Mean of the highest temperatures in a year & 0.426 & 0.0003 & $y=0.013 x-5.960$ & 0.65 \\
\hline Mean of the lowest temperatures in August & 0.396 & 0.0009 & $y=0.022 x-18.966$ & 1.10 \\
\hline Mean of the lowest temperatures in a year & 0.889 & $<0.0001$ & $y=0.048 x-82.257$ & 2.40 \\
\hline \multicolumn{5}{|l|}{ Hachijo island } \\
\hline Mean temperature in August & 0.008 & 0.9505 & $y=0.002 x+26.121$ & 0.01 \\
\hline Mean temperature in a year & 0.194 & 0.1152 & $y=0.005 x+9.067$ & 0.25 \\
\hline Mean of the highest temperature in August & -0.130 & 0.2938 & $y=0.004 x+38.272$ & -0.20 \\
\hline Mean of the highest temperature in a year & 0.073 & 0.5565 & $y=0.002 x+17.722$ & 0.10 \\
\hline Mean of the lowest temperature in August & 0.113 & 0.3625 & $y=0.004 x+17.188$ & 0.20 \\
\hline Mean of the lowest temperature in a year & 0.153 & 0.2175 & $y=0.004 x+7.593$ & 0.20 \\
\hline
\end{tabular}

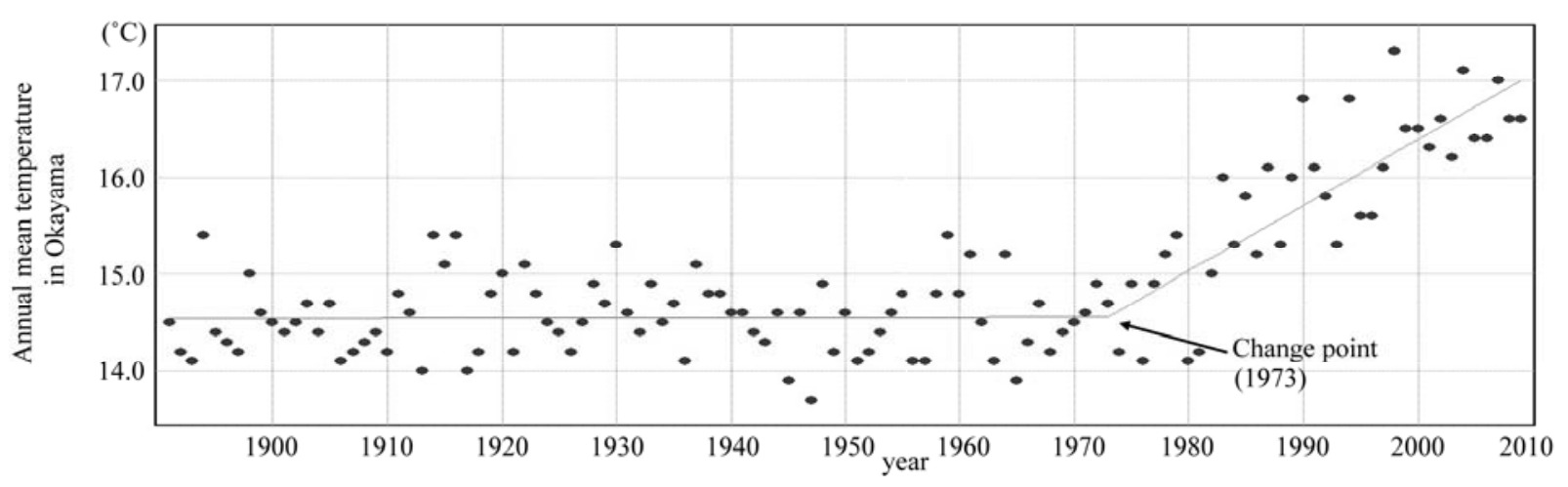

Figure 2. Change point of annual mean temperatures in Okayama, Japan (1891 2009). 
Table 3. Simple correlation analysis between years and number of days over various temperatures in August from 1961 to 2009.

\begin{tabular}{|c|c|c|c|c|c|c|c|c|}
\hline & \multicolumn{2}{|c|}{ Okayama area } & \multicolumn{2}{|c|}{ Tsuyama area } & \multicolumn{2}{|c|}{ Tokyo area } & \multicolumn{2}{|c|}{ Hachijo island } \\
\hline & $r$ & $p$ & $r$ & $p$ & $r$ & $p$ & $r$ & $p$ \\
\hline $\begin{array}{l}\text { Number of days over } \\
30^{\circ} \mathrm{C}\end{array}$ & 0.071 & 0.6301 & 0.053 & 0.7169 & 0.016 & 0.9113 & 0.118 & 0.4213 \\
\hline $\begin{array}{l}\text { Number of days over } \\
31^{\circ} \mathrm{C}\end{array}$ & 0.073 & 0.6184 & 0.004 & 0.9799 & 0.074 & 0.6127 & 0.107 & 0.4628 \\
\hline $\begin{array}{l}\text { Number of days over } \\
32^{\circ} \mathrm{C}\end{array}$ & 0.173 & 0.2346 & 0.086 & 0.5552 & 0.023 & 0.8731 & 0.085 & 0.5637 \\
\hline $\begin{array}{l}\text { Number of days over } \\
33^{\circ} \mathrm{C}\end{array}$ & 0.343 & 0.0159 & 0.069 & 0.6384 & 0.077 & 0.5968 & 0.058 & 0.6905 \\
\hline $\begin{array}{l}\text { Number of days over } \\
34^{\circ} \mathrm{C}\end{array}$ & 0.266 & 0.0643 & 0.101 & 0.4917 & 0.130 & 0.3748 & & \\
\hline $\begin{array}{l}\text { Number of days over } \\
35^{\circ} \mathrm{C}\end{array}$ & 0.407 & 0.0037 & 0.000 & 0.9978 & 0.125 & 0.3929 & & \\
\hline
\end{tabular}

\section{Discussion}

We firstly investigated the changes in parameters of temperatures among 4 different urbanization areas such as Okayama, Tsuyama, Tokyo areas and Hachijo Island, Japan. Parameters of temperatures were gradually increased with years in Okayama area, especially in recent years. In addition, the change point of 1973 in mean temperature may be reflected that heat island effect in Okayama area was remarkably accelerated.

According to the research of Osaka in Japan, the mean warming rate in Osaka surface air temperature is about $2.0^{\circ} \mathrm{C}$ over the period from 1883 to 2006 , at least half of which can be attributed to the urban heat island effects [12]. However, this surface air temperature warming was not as strong as the ground warming recorded in the subsurface temperature profiles. Therefore, the anthropo- genic thermal impacts on the subsurface can be more persistent and profound than the impacts on the atmosphere.

Taniguchi et al. reported that subsurface environmental indicators were evaluated from three points of view i.e. human activities, climate change, and character of urbanization and social policies. Heat island effect due to urbanization creates subsurface thermal contamination in many cities [13]. Average subsurface temperature profiles in four Asian cities (Tokyo, Osaka, Seoul and Bangkok) were compared and analyzed to evaluate the effects of surface warming [14]. The magnitude of surface warming is evaluated to be the largest in Tokyo $\left(2.8^{\circ} \mathrm{C}\right)$, followed by Seoul, Osaka and Bangkok. And this observation showed mean depth of deviation from the regional geothermal gradient in each urban area may be a useful indicator of the history of urbanization. The combination of the heat island effect due to urbanization and global warming on subsurface temperatures also relates to global ground water quality issues. This relationship holds because increased subsurface temper- atures alter the ground water system chemically and microbiologically [15].

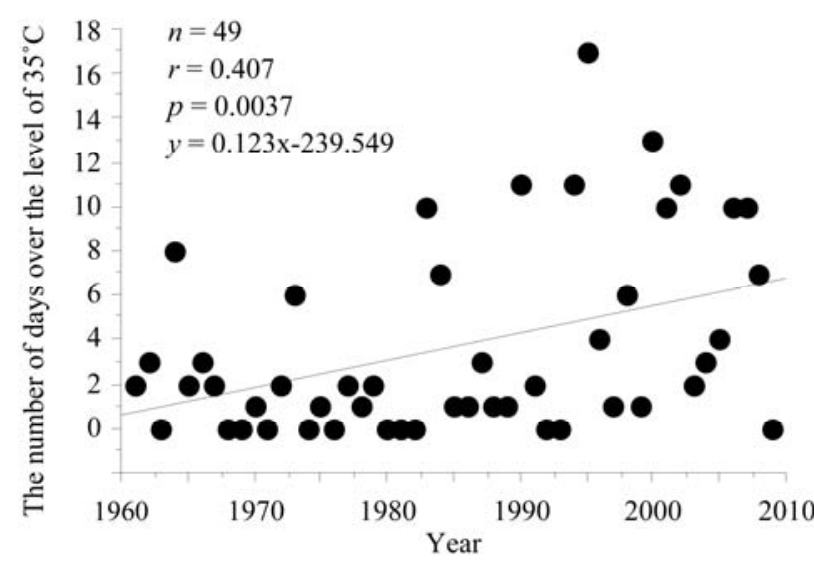

Figure 3. Simple correlation analysis between the number of days over $35^{\circ} \mathrm{C}$ and years in Okayama area, Japan (1961 2009).

In some previous reports, the relation between high temperatures and heat stroke in Japan [16-18]. Nakai et al. investigated heat-related deaths in Japan from 1968 through 1994 and heat-related deaths were most prone to occur on days with a peak daily temperature above $38^{\circ} \mathrm{C}$ [16]. In addition, they reported that incidence of heatrelated deaths showed and exponential dependence on the number of hot days [16]. Piver et al. reported that heat stroke was associated with prolonged exposures to higher air temperatures that usually occur in the summer months of July and August in 1980-1995 in Tokyo. Residents in Tokyo were also often exposed simultaneously to high concentrations of air pollutants [17]. Qui et al. reported that an unusual hot spell in 1999 was followed by a high mortality rate in Hokkaido, Japan [18]. We have also previously showed that higher temperatures were closely linked to ambulance transports in Okayama area, Japan [11].

In this study, we compared points of change in mean temperature among 4 areas, and we found that point of 
change in mean temperature in Tokyo was 1921, that in Okayama was 1973 and that in Tsuyama was in 1984. Therefore, it seems reasonable to suggest that simply dealing with heat island effect in Okayama area i.e. innovation of the thermal energy metabolism in cities and individual coping with high temperatures is urgently required in Okayama as well as Tokyo area, Japan. In addition, the point of change in mean temperature may be good parameter of urbanization in Japan.

Potential limitation still remains in this study. The changes in parameters of temperatures, which were noted in 4 areas, may not apply for all areas in Japan. Therefore, we could not accurately evaluate the changes in temperatures in Japan. Further studies are required to prove the changes in temperatures and heat island effect in Japan.

In conclusion, the mean temperature in Okayama area is rising intentionally higher than that in Tokyo area, especially in recent years. The number of days of over $33^{\circ} \mathrm{C}$ and $35^{\circ} \mathrm{C}$ in only Okayama area was significantly correlated with years.

\section{Acknowledgements}

We gratefully thank to Mrs. Michiyo Mitani for assistance of data preparation.

\section{REFERENCES}

[1] IPCC, "Climate Change 2007, Fourth Assessment Report of the Intergovenmental Panel on Climate Change (IPCC)," Cambridge University Press, Cambridge, 2007.

[2] J. Tan, L. S. Kalkstein, J. Huang, S. Lin, H. Yin and D. Shao, "An Operational Heat/Health Warning System in Shanghai," International Journal of Biometeorology, Vol. 48, No. 3, 2004, pp. 157-162. doi:10.1007/s00484-003-0193-z

[3] C. Schär, P. L. Vidale, D. Lüthi, C. Frei, C. Häberli, M. A. Liniger and C. Appenzeller, "The Role of Increasing Temperature Variability in European Summer Heatwaves," Nature, Vol. 427, No. 6972, 2004, pp. 332- 336.

[4] P. A. Stott, D. A. Stone and M. R. Allen, "Human Contribution to the European Heatwave of 2003," Nature, Vol. 432, No. 7017, 2004, pp. 610-614. doi:10.1038/nature03089

[5] K. E. Smoyer, "A Comparative Analysis of Heat Waves and Associated Mortality in St. Louis, Missouri - 1980 and 1995," International Journal of Biometeorology, Vol. 42, No. 1, 1998, pp. 44-50. doi: $10.1007 / \mathrm{s} 004840050082$

[6] W. Buermann, B. R. Lintner, C. D. Koven, A. Angert, J. E. Pinzon, C. J. Tucker, et al., "The Changing Carbon Cycle at Mauna Loa Observatory," Proceedings of the National Academy of Sciences USA, Vol. 104, No. 11, 2007, pp. 4249-4254. doi:10.1073/pnas.0611224104
[7] D. Lüthi, M. L. Floch, B. Bereiter, T. Blunier, J. M. Barnola, U. Siegenthaler, D. Raynaud, J. Jouzel, H. Fischer, K. Kawamura and T. F. Stocker, "High-Resolution Carbon Dioxide Concentration Record 650 000- 800000 years before Present," Nature, Vol. 453, No. 7193, 2008, pp. 379-382.

[8] C. Schär and G. Jendritzky, "Climate Change: Hot News from Summer 2003," Nature, Vol. 432, No. 7017, 2004, pp. 559-560.

[9] A. Haines and J. A. Patz, "Health Effects of Climate Change,” JAMA, Vol. 291, No. 1, 2004, pp. 99-103. doi:10.1001/jama.291.1.99

[10] C. Aniello, K. Morgan, A. Busbey and L. Newland, "Mapping Micro-Urban Heat Islands Using LANDSAT TM and a GIS," Computer Geosciences, Vol. 21, No. 8, 1995, pp. 965-969. doi:10.1016/0098-3004(95)00033-5

[11] N. Sakano, N. Miyatake, T. Suzue, S. Suna, T. Hirao and K. Ogino, "The Relation between High Temperatures and Ambulance Transports in Okayama City, Japan,"Journal of Preventive Medicine, (in Japanese), (in press).

[12] S. Huang, M. Taniguchi, M. Yamano and C. H. Wang, "Detecting Urbanization Effects on Surface and Subsurface Thermal Environment - a Case Study of Osaka," Science of the Total Environment, Vol. 407, No. 9, 2009, pp. 3142-3152. doi:10.1016/j.scitotenv.2008.04.019

[13] M. Taniguchi, W. C. Burnett and G. D. Ness, "Integrated Research on Subsurface Environments in Asian Urban Areas," Science of the Total Environment, Vol. 404, No. 2-3, 2008, pp. 377-392. doi:10.1016/j.scitotenv.2008.04.033

[14] M. Taniguchi, T. Uemura and K. Jago-On, "Combined Effects of Urbanization and Global Warming on Subsurface Temperature in four Asian Cities," Vadose Zone Journal, Vol. 6, No. 3, 2007, pp. 591-596. doi:10.2136/vzj2006.0094

[15] W. Knorr, I. C. Prentice, J. I. House and E. A. Holland, "Long-Term Sensitivity of Soil Carbon Turnover to Warming," Nature, Vol. 433, No. 7023, 2005, pp. 298-301. doi:10.1038/nature03226

[16] S. Nakai, T. Itoh and T. Morimoto, "Deaths from Heat-Stroke in Japan: 1968-1994," International Journal of Biometeorology, Vol. 43, No. 3, 1999, pp. 124-127. doi:10.1007/s004840050127

[17] W. T. Piver, M. Ando, F. Ye and C. J. Portier, "Temperature and Air Pollution as Risk Factors for Heat Stroke in Tokyo, July and August 1980-1995," Environ Health Perspect, Vol. 107, No. 11, 1999, pp. 911-916. doi:10.1289/ehp.99107911

[18] D. Qiu, T. Tanihata, H. Aoyama, T. Fujita, Y. Inaba and M. Minowa, "Relationship between a High Mortality Rate and Extreme Heat during the Summer of 1999 in Hokkaido Prefecture, Japan," Journal of Epidemiolody, Vol. 12, No. 3, 2002, pp. 254-257. 